\title{
Construction of Network Security Law Enforcement Virtual Simulation Experiment and Teaching Platform
}

\author{
Yang Yang* \\ Department of computer and information security, Zhejiang police college, Hangzhou 310053, China \\ ${ }^{*}$ Corresponding author. Email: 695671400@qq.com
}

\begin{abstract}
In view of the problems in virtual simulation experiment teaching of network security law enforcement, this paper analyzes the necessity of construction of the virtual simulation experiment teaching platform, which expounds the construction content of virtual simulation experiment platform from three aspects of virtual simulation course system, experimental space and teaching mode. Network security law enforcement virtual simulation experiment and teaching platform is constructed with three core experimental modules of network security scene law enforcement, electronic data scene forensics, and investigation of cyber-crime cases. The training of students' higher order thinking and actual combat ability is strengthened in public security colleges.
\end{abstract}

Keywords: Virtual simulation, Experimental teaching platform, Network security law enforcement.

\section{INTRODUCTION}

Virtual simulation experiment teaching is an important content of higher education information construction and experimental teaching demonstration center construction, and is the product of the deep integration of discipline and information technology [1]. At present, traditional crimes in China are gradually shifting to the Internet, and cyber crimes are frequently and frequently occurring, seriously endangering national security, social order and people's interests. The forging of a team of high-quality professionals in network security and law enforcement is the inevitable path to effectively crack down on network crimes and realize the comprehensive governance of network crimes, and also provides a new examination question for the teaching of network security law enforcement [2-3].

In view of the network security law enforcement routine practice teaching cannot cover all types of the experiment, especially some reach or irreversible operations (such as electronic data on-site inspection, etc.), and need high cost, large comprehensive experiments training (such as a variety of types involved network crimes probing experiment, etc.), virtual simulation experiment teaching has become a important method in the teaching of network security law enforcement [4-5]. Therefore, combining with the characteristics of network security law enforcement major, exploring the establishment of virtual simulation experimental teaching platform for network security law enforcement plays a crucial role in the teaching of network security law enforcement experiment and practical training[6-7].

\section{THE NECESSITY OF CONSTRUCTING VIRTUAL SIMULATION EXPERIMENTAL TEACHING PLATFORM FOR NETWORK SECURITY LAW ENFORCEMENT}

One is to solve the problem of poor learning experience. Virtual simulation experimental teaching platform uses VR technology to create virtual simulation law enforcement and case handling scenes, and transfers real case data to the simulation environment to improve the immersion and participation of experimental operation. Second, solve the problem of time and space limitation. The virtual simulation experimental teaching platform can extend the time of students' experimental operation and learning, solve the problems such as the long time of disk cloning experiment and the difficulty in setting up the on-site inspection environment, and let students get rid of the limitations of physical space and teaching time in the laboratory. Third, solve the problem of the irreversible process of cyber security law enforcement. The volatilities of electronic evidence mean that the process of cyber security law enforcement faces irreversible risks. Moreover, there are complex, 
professional and sudden problems in the process of network security law enforcement, which are difficult to be repeated in the real environment. The virtual simulation experimental teaching platform can guarantee the integrity and authenticity of data on the basis of security, stability and reliability.

\section{CONTENT OF CONSTRUCTION OF VIRTUAL SIMULATION EXPERIMENTAL TEACHING PLATFORM FOR NETWORK SECURITY LAW ENFORCEMENT}

Under the background of public security education informatization, in order to combat ability training as the guide, combining with the web technology and VR technology, the network security and law enforcement and the depth of information technology integration of disciplines, build "for actual combat, reality, to effect" of the curriculum system, building of three-dimensional, open and multi-level experiment space, build the "three step progressive, four modernizations fusion, three provinces gauge" mode of teaching, to improve public security universities and colleges students of higher order thinking and innovation ability, advance the informatization construction of police schools teaching and experimental teaching reform and development [8].

\subsection{Construct a Course System that is "oriented to actual combat, close to reality and practical effect"}

The cyber security law enforcement curriculum system should closely follow the top-level design of professional talent training program, always be practical and result-oriented, make clear the forward-looking training objectives, and highlight the relevance of target courses. Focusing on the training of the three major capabilities of network security law enforcement, the modular reconstruction of the experimental teaching items and contents was carried out, and three modules of network security field law enforcement, electronic data field investigation, and network related case investigation and deduction were constructed. Among them, the network security on-site law enforcement experiment is a demonstration experiment, which focuses on training students to master the network security onsite law enforcement process systematically. The electronic data scene investigation experiment is a comprehensive experiment, which is the key point of the network security law enforcement experiment course. The main content is the standard process of the electronic data scene investigation, and pays attention to the cultivation of students' awareness of electronic evidence preservation and technical ability of evidence collection. The inference experiment of internet-related cases investigation and handling is an innovative experiment, with the main content of typical internet-related cases investigation and handling ideas and methods, and focuses on cultivating students' innovative ability of investigating and collecting evidence in internet-related cases.

Among them, the experimental level, from elementary to intermediate, from intermediate to advanced; In terms of experiment types, from demonstration experiment to comprehensive experiment, and then to innovative experiment, the hierarchical progressive experiment model of small class was explored. In terms of experimental materials, it derives from actual combat and serves actual combat. It quotes the most vivid actual combat cases from the front line of the police, works with the resident instructors to build an experimental teaching team, advocates inquiry-based, heuristic and discuss-style practical teaching, and promotes the extension of experimental and practical training to the front line of actual combat of the police.

\subsection{Build a "three-dimensional, open and multi-level" Experimental Space}

After the outbreak of COVID-19, the Ministry of Education put forward the work requirement of "no suspension of classes", and nationwide schools carried out large-scale and organized online education and teaching during the epidemic prevention and control period, which is of great significance to the promotion of education and teaching reform by using information means. Meanwhile, higher requirements are put forward for the systematization and functionality of the online experimental platform. In line with the resource sharing, "teaching, learning, practice," the design concept of integration, virtual simulation experiment teaching platform on network security law enforcement has carried on the structure optimization, improve the period of conventional and unconventional, "everyone can learn, to learn all the time, everywhere can learn" learning space construction, building of threedimensional, open and multi-level experiment space [9].

Three-dimensional refers to the teaching content, based on the network security and law enforcement major teaching experiment outline framework, so that the basic theory of experimental training; In terms of teaching methods, online and offline teaching should be integrated to fully embody the principle of "combination of virtual and real" to carry out diversified simulation teaching experimental projects. Openness is open to students and teachers $24 / 7$. It not only provides students with time and space for cyber security law enforcement training, so that students can continue to deepen and improve in their spare time, but also builds a platform for teachers to grow in scientific research, so that scientific research feeds back teaching. Multi-level is education of record of formal schooling and go hand in hand, police training teaching experiment platform based on network security law enforcement, law enforcement can carry out network 
security skills contest, to practice promotion, whereas, in order to speed up network security theory knowledge and practice fusion, inspire the motivation for students majoring in network security and law enforcement, improve the students' active learning and expanding the ability to think. At the same time, police training should be carried out around hot topics, and professional training should be optimized in combination with the working situation of public security and cutting-edge technologies, so as to enhance the theoretical, targeted and practical aspects of police training.

\subsection{Build a Teaching Model of "Three-step Progression, Four Modernizations and Three Provincial Gauges"}

The three-step gradualism refers to the establishment of a step-by-step hierarchical system, with the primary stage oriented to general knowledge, the intermediate stage oriented to specialty, and the advanced stage oriented to practical practice. In the primary stage, general education will be carried out for undergraduates who are not majoring in cybersecurity and law enforcement, and immersive game experience mode will be adopted to master the standard awareness of electronic forensics. In the intermediate stage, we will carry out professional core education for undergraduates majoring in cybersecurity and law enforcement, using case analysis and experimental simulation mode, and focusing on mastering the on-site inspection process and electronic data analysis technology. The senior stage focuses on cultivating the practical ability of network security law enforcement for all students and trainees.

The integration of the four modernizations refers to the organic integration of interaction and participation, practical cases, immersive experiments and ideological and political courses, and the construction of a highquality experimental classroom education system. Interactive participation means to adhere to the studentcentered, use big data to carry out learning situation analysis, teach students in accordance with their aptitude, implement precise strategies, design participatory teaching strategies and methods in line with a variety of learning styles, and carry out all-round, effective and deep interaction. Case practice means that on the basis of the good mechanism of "school-bureau cooperation and school-enterprise cooperation", the "teaching-practical community" is jointly built, and the investigation activities of public security business are deeply carried out, and the classic cases and typical problems of law enforcement in the field of network security are collected, so as to accumulate first-hand case materials for teaching and scientific research work [10]. Experimental immersion is based on the network security law enforcement actual combat teaching platform, the introduction of VR virtual reality technology, highlighting the immersive experimental experience, so that students can truly perceive the electronic inspection site, in order to pass the test, question and answer and immersive experience, learning electronic data extraction and fixed technology and norms, stimulate students' interest in learning; The ideological and political orientation of curriculum means to carry out the construction of professional ideological and political education deeply, to integrate the educational resources of condensed professional courses, to carry out ideological and political education silently and to improve the educational effect.

The three provincial gauges mean that the experimental results and final results are no longer taken as the single assessment basis, but pay more attention to the process assessment, improve the formative assessment, and build a relatively fair and reasonable diversified course evaluation system and detailed gauges. Through online time, communication and interaction, platform log, intelligent evaluation and other ways to evaluate the process, result and effect feedback of the three aspects of comprehensive evaluation.

\section{CONSTRUCTION OF VIRTUAL SIMULATION EXPERIMENTAL TEACHING PLATFORM FOR NETWORK SECURITY LAW ENFORCEMENT}

The virtual simulation experimental teaching platform for network security law enforcement is composed of network security field law enforcement experiment module, electronic data field investigation experiment module, and network-related case investigation and deduction experiment module. The platform focuses on the construction of experimental projects and organically combines demonstrative, comprehensive and innovative teaching experiments according to the experimental knowledge structure, students' learning characteristics and talent cultivation programs. Adhere to the "trinity" education concept of value guidance, knowledge impart and ability cultivation, expand the breadth and depth of experimental teaching content, and strengthen the important role of professional education in cultivating loyal, reliable, intelligent and courageous high-quality police personnel [11]. With the construction of "integration of teaching, practice and war" as the cornerstone of the experimental teaching platform, it carries out practical teaching reform of experimental and practical training projects, creates a database of high-quality experimental and practical training projects, strengthens the cultivation of students cybersecurity values, and serves the ultimate training goal of "cybersecurity law enforcement talents".

\subsection{Network Security Field Law Enforcement Experiment Module}

The main content of the network security on-site law enforcement module is to simulate network security 
protection and supervision of site management for law enforcement objects such as network owners, managers and network service providers according to the relevant laws and regulations such as the Network Security Law and Information Security Levels Protection and Management Measures. The network security on-site law enforcement module can simulate supervision, inspection, law enforcement and other work links in virtual scenes to carry out actual combat simulation training. The main business scenarios include on-site law enforcement business scenarios for Internet access, Internet data center, content distribution, and domain name service units; For the scene law enforcement business scenarios of units providing Internet information services; For providing public Internet service units of the scene law enforcement business scenarios. The contents of law enforcement include network security management system, network security operating procedures and network security level protection.

\subsection{Electronic Data Field Investigation Experiment Module}

The electronic data scene investigation experiment module is the core module of virtual simulation experiment teaching platform of network security law enforcement. In accordance with relevant laws and regulations, such as the Regulations on the Collection, Extraction, Examination and Judgment of Electronic Data in Handling Criminal Cases and the Regulations on the Handling of Electronic Data Evidence in Criminal Cases by Public Security Organs of the Ministry of Public Security (2019), there are strict guidelines for the investigation of electronic data at the scene of online cases. the electronic data on-site experiment module for cases involving network for the technology of electronic data decomposition, including the exploration of preparation, on-site security, the scene photos, electronic data search, computer data extraction fixed, mobile phone data extraction, extraction and fixed wireless network, fill in the field exploration instrument, electronic equipment storage and comprehensive field exploration data and other process elements [12].

The electronic data scene exploration experiment module is based on virtual simulation interactive animation, supplemented by superposition of video, voice, text and picture, to simulate the case scene and the standard process of electronic forensics. users can interact with people or objects in the scene step by step according to the prompts. The system can intelligently identify user operations and guide users to trigger the case handling process step by step according to the operating standards and quality, so as to complete the inspection experiment of the whole process of network security law enforcement. The virtual simulation interactive operation fully mobilizes students' hands and brains, cultivates students' logical thinking ability of onsite investigation, and consolidates students' mastery of electronic forensics knowledge.

\subsection{Internet-related Case Investigation and Deduction Experiment Module}

The network related case investigation and deduction experiment module is an important module of virtual simulation experiment teaching platform of network security law enforcement. Facing the new situation and new forms of cyber-related crimes, students majoring in cybersecurity law enforcement must understand and be familiar with the investigation and handling process of cyber-related crimes. Cases involving network inference carried experiment module based on all kinds of typical cases involving network crime case documents (files) materials, custom development involving network case for case simulation training system, will be called, police and now can be, visits, case analysis, technical appraisal, summoned, interrogation, capture and a series of cases probing process digital processing and handling of standardization process of the teaching design and display, in scene simulation, the interactive teaching, case analysis, expert review for cases involving network deal with standardized business skills of network experimental teaching training [13].

The model of inference experiment of internet-related case investigation adopts the path of case design $\rightarrow$ inference training $\rightarrow$ scoring feedback to carry out inference experiment of internet-related case investigation. Case design refers to the script design around the network gambling, network fraud, network pornography, network theft, illegal computer intrusion and other five categories of cases. Deductive training refers to the use of text and pictures mixed, audio and video assisted visual display of the case events, guide students to simulate the exercise on the computer alone, students gradually answer in accordance with the steps of deduction and simulate the handling of the case. The grading feedback refers to the intelligent evaluation system based on the students' individual answers and the case investigation process.

\section{CONCLUSION}

Through the integration of information technology, intelligent technology and public security education, we insist on the integration of inside and outside school, inside and outside class, systematically integrate virtual simulation experimental teaching resources, and create a batch of mixed "golden classes" that "combine reality with reality and complement each other". Based on the cooperation mechanism between the school and the bureau, combining with the characteristics of the network security law enforcement professional course chain, we will build a virtual simulation experimental teaching team of "police and education integration and 
collaborative education". In accordance with the principle of combining services with resources, the virtual simulation experiment teaching platform of network security law enforcement is built, and the actual combat teaching reform is deeply promoted. With the goal of cultivating high-quality police personnel of network security law enforcement, the high-level thinking and actual law enforcement ability of students are constantly improved.

\section{ACKNOWLEDGMENTS}

This research was financially supported by The second batch of teaching reform research projects of higher education in Zhejiang Province during the 13th FiveYear Plan (Project No.: jg20190497).

\section{REFERENCES}

[1] General Office of the Ministry of Education. About 2015 national virtual simulation experiment teaching centerconstruction notice [EB/OL]. (201506-04)[2019-07-25].

http://www.moe.gov.cn/srcsite/A08/s7945/s7946/2 01506/t20150618_190671.html.

[2] Zhou Yijin, Jiang Junping. Construction of intelligent experimental platform for police "actual combat teaching" [J]. Experimental Technology and Management,2018,35(03):233-236+243.

[3] Gao Song, Wang Bin. Experimental Technology and Management,2011,28(08):226-228.

[4] Su Na. Constructing the Practical Teaching System of Public Security Management Specialty Oriented byVocational Ability [J]. Experimental Technology and Management,2014,31(08):203-207.

[5] Yin Junzu, Gao Hang, Le Xinyu. Research and practice of police training teaching in police colleges[J].Experimental Technology and Management,2010,27(03):219-221.

[6] Xie Haijun. Research on the Construction of Practical Education Base in Police Colleges [J].Laboratory Research and Exploration,2018,37(09):261-265.

[7] Lu Furong, Wu Guihua, Wang Jingqiang, Liu Jianhua, Ding Xin. Construction of tourism virtual simulation experimental teaching system [J]. Experimental Technology and Management,2020,37(01):167-170+195.

[8] Fang Hanping. Construction and Practice of Collaborative Management Platform for Information-based PoliceExperiment and Training [J]. Laboratory Research and Exploration,2019,38(11):261-265.
[9] Liu Jianming, Xu Lili, Liang Shujuan, Wang Yiguang. Construction and practice of medical wisdom informationization experimental training teaching platform $[\mathrm{J}]$. Experimental Technology and Management,2020,37(02):245-248.

[10] Wang Xiaobin, Xu Shaohui. Practice of the construction of experimental teaching center of criminal science and technology $[\mathrm{J}]$. Laboratory Research and Exploration,2019,38(01):137-140.

[11] Gao Wei, Dai Dongxu. "Police Education Integration and Collaborative Education" Innovative New Model of Public Security Education -- A Case Study of Zhejiang Police College Outstanding Police Talents Training Model Reform [J]. Journal of Guangxi Police College,2019,32(06):105-110.

[12] Yang Fuqiang, Yang Jian. Construction of virtual simulation experimental teaching platform for safety engineering specialty [J]. Experimental Technology and Management,2020,37(03):242$245+254$.

[13] LIN Z W, YANG S H, HUANG L F. Construction of plant experimental teaching system combining Web and VR [J]. Experimental Technology and Management,2020,37(02):144-147. 